УДК 656.1.025.2(1-21):004

https://doi.org/10.24866/1813-3274/2021-1/38-52

Е. М. Волкова ${ }^{1}$, Петербургский государственный университет путей сообщения Императора Александра I, г. Санкт-Петербург, Россия E-mail: moonlight34@ya.ru

В. М. Колесова ${ }^{2}$, Петербургский государственный университет путей сообщения Императора Александра I, г. Санкт-Петербург, Россия E-mail: vkolesova08@rambler.ru

\title{
ПОСТРОЕНИЕ ГОРОДСКОЙ ТРАНСПОРТНОЙ СИСТЕМЫ НА БАЗЕ ИНТЕЛЛЕКТУАЛЬНЫХ ТЕХНОЛОГИЙ
}

Аннотация. На сегодняшний день актуальны проблемы взаимодействия видов пассажирского транспорта в крупных городах. Концентрация населения в мегаполисах и высокие темпы автомобилизации приводят к нерациональному распределению пассажиропотоков по видам транспорта, неэффективному использованию ресурсов транспортного комплекса, значительным потерям времени в пути. Решение перечисленных проблем должно быть комплексным. В первую очередь оно предполагает кооперацию субъектов рынка транспортных услуг по собственной инициативе, то есть формирование «бесшовной» городской транспортной системы. С другой стороны, резервы повышения эффективности использования ограниченных ресурсов кроются в применении цифровых технологий. В статье показаны результаты применения алгоритма «умного» дорожного регулирования на выбранном объекте транспортной инфраструктуры. Данные результаты получены в ходе эксперимента в среде имитационного моделирования Anylogic. По итогам исследования обозначены перспективы применения цифровых технологий в городских транспортных системах и поставлен вопрос о сложности экономической оценки эффектов, генерируемых подобными проектами.

\footnotetext{
${ }^{1}$ Елена Михайловна Волкова, кандидат экономических наук, доцент, доцент кафедры «Экономика транспорта» Петербургского государственного университета путей сообщения Императора Александра I, г. Санкт-Петербург, Россия.

2 Валентина Михайловна Колесова, кандидат экономических наук, доцент, доцент кафедры «Менеджмент и маркетинг» Петербургского государственного университета путей сообщения Императора Александра I, г. Санкт-Петербург, Россия.

Для циитирования: Волкова Е. М., Колесова В. М. Построение городской транспортной системы на базе интеллектуальных технологий // Азиатско-Тихоокеанский регион: экономика, политика и право. 2021. № 1. C. 38-52. https://doi.org/10.24866/1813-3274/2021-1/38-52.
}

(C) Волкова Е. М., Колесова В. М., 2021 
Ключевые слова: городская транспортная система, агломерация, мегаполис, цифровизация, «бесшовная» транспортная система, дорожное регулирование, имитационное моделирование, перекрёсток, транспортная инфраструктура.

Elena M. Volkova ${ }^{1}$, Emperor Alexander I Petersburg State Transport University, St. Petersburg, Russia

E-mail: moonlight34@ya.ru

Valentina M. Kolesova ${ }^{2}$, Emperor Alexander I Petersburg State Transport University, St. Petersburg, Russia

E-mail: vkolesova08@rambler.ru

\section{DEVELOPMENT OF URBAN TRANSPORT SYSTEM BASED ON DIGITAL TECHNOLOGIES}

Abstract. Nowadays, problems of interaction between passenger transport modes in large cities are relevant. Concentration of population in megacities and the high level of motorization lead to ineffective distribution of passenger flows between different modes of public and private transport, decreasing of the economic efficiency of urban transport systems, wasting time by passengers and drivers. Solution of these problems should be comprehensive. At first, it should be based on the cooperation of transport companies in a seamless transport system. On the other hand, possibilities of increasing the effectiveness of urban passenger transport lie in digital technologies implementation. In this research, one direction of digitalization of urban transport system is highlighted: implementation of smart technologies for road traffic management. These results are based on the experiment in AnyLogic software. Perspective ways of digital technologies implementation in urban transport systems are highlighted.

Keywords: urban transport system, agglomeration, megacity, digitalization, seamless transport system, road traffic regulation, simulation modeling, crossroad, transport infrastructure.

\footnotetext{
${ }^{1}$ Elena Mikhailovna Volkova, Associate Professor of Department of Economics of Transport, Emperor Alexander I Petersburg State Transport University, St. Petersburg, Russia.

${ }^{2}$ Valentina Mikhailovna Kolesova, Associate Professor of Department of Management and Marketing, Emperor Alexander I Petersburg State Transport University, St. Petersburg, Russia.

For citing: Volkova E. M., Kolesova V. M. Development of urban transport system based on digital technologies // PACIFIC RIM: Economics, Politics, Law. 2021. No 1. P. 38-52. https://doi.org/10.24866/1813$3274 / 2021-1 / 38-52$.
} 


\section{1. Эволюция подходов к управлению городскими транспортными системами}

Подходы к развитию городских транспортных систем в последние полвека менялись в соответствии с одним из философских законов диалектики - законом отрицания отрицания, сформулированным Г. Гегелем. Сущность данного закона в упрощенном виде можно описать как закономерность цикличного развития явления или процесса в три условных этапа, характеризующихся определённой степенью преемственности: от исходного состояния к противоположному, а затем к очередному состоянию, в котором можно обнаружить ряд сходств с исходным. Образно это можно представить как развитие «по спирали», где каждый новый виток сохраняет некоторые черты прежнего. Попытаемся проиллюстрировать действие данного закона на примере эволюции подходов к управлению отечественными транспортными системами.

В период директивного планирования экономики (XX век) управление развитием транспортных систем на всех уровнях (национальном, региональном, местном) осуществлялось централизованно, исходя из поставленных целей, уровня развития транспортной инфраструктуры, объективных характеристик видов общественного пассажирского транспорта. Целью управления была минимизация общественно необходимых затрат на перевозки при выполнении запланированных значений объёмных и качественных показателей. Транспортные системы в тот период отличались высоким уровнем согласованности всех видов общественного пассажирского транспорта. Так, в 1967 г. в постановлении Совета Министров СССР была закреплена обязанность горисполкомов крупных городов (более 250 тыс. чел.) разрабатывать комплексные транспортные схемы развития всех видов пассажирского транспорта. Учёные и специалисты в области транспорта занимались методологией построения единых транспортных систем разного уровня. Например, в работе Э. В. Шабаровой [9] отмечается отсутствие единой методики разработки комплексной транспортной схемы для городских агломераций и предложен подход к их построению.

Переход к системе рыночных отношений (рубеж XX-XXI вв.) сопровождался децентрализацией управления транспортными системами при сохранении необходимых функций государственного регулирования. Сформировались многочисленные рынки транспортных услуг, которые в зависимости от локализации и иных многочисленных факторов приобрели характерные черты монополии, олигополии или работающей конкуренции. Обострение межвидовой конкуренции в последнее десятилетие было обусловлено сокращением ёмкости рынка пассажирских перевозок, вызванным прежде всего ускоренной автомобилизацией. Очевидно, что конкурентные преимущества транспортной организации по-прежнему определяются особенностями технологии перевозки, характерной для того или иного вида транспорта, и уровнем развития транспортной инфраструктуры. 
С переходом к рыночным отношениям связи между транспортными организациями в городском и пригородном сообщении во многом потерялись. Планирование размеров движения городского пассажирского транспорта осуществляется на основе имеющейся сети маршрутов, а развитие конкуренции «за маршрут» предполагает процедуру выбора перевозчика путём проведения конкурсных процедур региональными органами исполнительной власти.

Однако в ряде случаев интенсивное развитие межвидовой конкуренции на рынках пассажирских перевозок не способствовало росту эффективности функционирования транспортных систем. Например, в мегаполисах появились многочисленные дублирующие маршруты разных видов общественного транспорта, произошёл массовый отток пассажиров на личный автотранспорт, что стало причиной потерь времени в заторах на автодорогах и ухудшения экологической ситуации, привело к ряду иных транспортных проблем. Сложившуюся ситуацию можно проиллюстрировать парадоксом Доунса-Томсона, который был выявлен ещё в середине прошлого века в ходе математического моделирования транспортных потоков, а также парадоксом Браеса. Суть первого парадокса состоит в следующем: существует прямая зависимость скорости движения частных транспортных средств (автомобилей) от средней скорости движения городского общественного транспорта. Объясняется это переходом пассажиров с общественного транспорта на личный из-за того, что изначальное уменьшение спроса вынуждает транспортные организации увеличивать интервалы движения транспортных средств, тем самым порождая дополнительный отток. Парадокс Браеса по смыслу схож с одним из следствий парадокса Доунса-Томсона и гласит о том, что расширение городской транспортной сети при независимом поведении её элементов (например, как в мультимодальной транспортной системе) может привести к снижению эффективности её функционирования. Объясняется данный факт тем, что при появлении дополнительной полосы движения водители личного автотранспорта, ранее стремившиеся совершить поездку во внепиковые часы (например, ранним утром), начинают выезжать на дорогу в часы «пик». Это, в свою очередь, приводит к резкому росту транспортных потоков и возникновению ещё больших заторов на расширенной автодороге. Перечисленные парадоксы ещё в 1960-х гг. стимулировали разработку новых подходов к управлению развитием городских транспортных систем в рыночной экономике.

Участники рынка транспортных услуг, а также регулирующие государственные органы в настоящий период осознают необходимость частичного отказа от конкурентной борьбы и возвращения к кооперации видов транспорта (в этом и проявляется, на наш взгляд, действие философского закона отрицания отрицания). Однако в рыночных условиях основой кооперации не сможет стать централизованное управление, как это было в плановой экономике. Она должна развиваться на основе взаимовыгодного сотрудничества субъектов рынка пассажирских перевозок при 
поддержке регулирующих органов. Необходимым условием кооперации становится и ощутимая выгода для пользователей транспортных услуг - пассажиров, которая выражается прежде всего в сокращении времени поездок.

Факторы, обеспечивающие сокращение общего времени мультимодальных поездок, представлены на рис. 1.

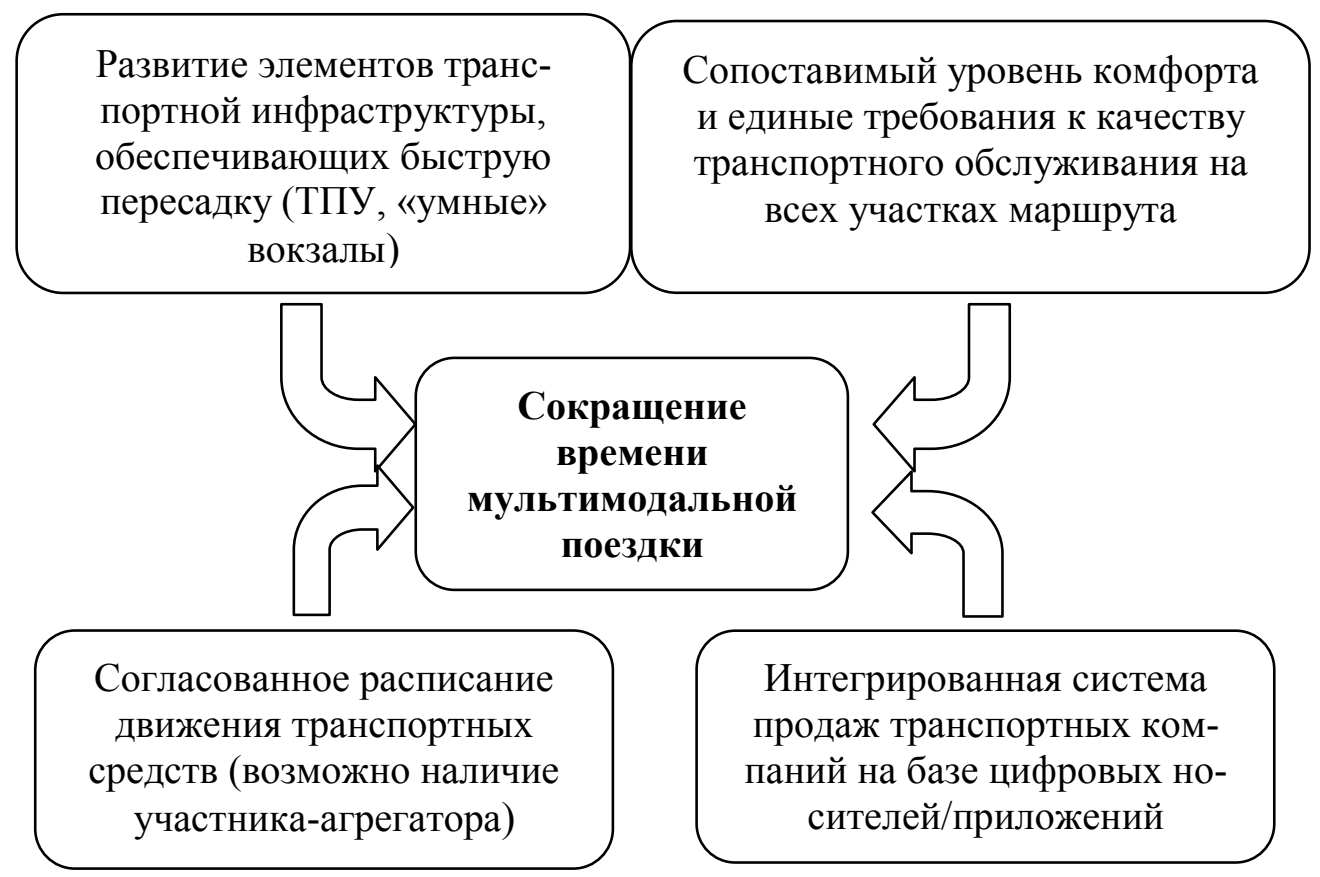

Puc. 1. Факторы, обеспечивающие сокращение общего времени мультимодальной пассажирской перевозки

Транспортные системы нового типа, основанные на интеграции видов транспорта в рыночных условиях, обозначаются в литературе терминами «интермодальные», «мультимодальные», «смешанные» или «бесшовные» (от англ. seamless). Ecли речь идёт о грузовых перевозках, терминология в этой области гораздо более обширна: так, известны многочисленные трактовки терминов «мультимодальная перевозка», «интермодальная перевозка», «комбинированная перевозка». Всё чаще говорят о концепции синхромодализма, под которым понимается возможность оперативной смены вида транспорта и пересмотра логистической схемы в процессе перевозки с целью максимизации её эффективности. Автор не ставит целью уточнение терминологии в данной области, однако обращает внимание на её разнообразие. В пассажирских перевозках всё чаще и исследователи, и корпоративный менеджмент используют понятие «бесшовная транспортная система», поэтому далее будет использоваться именно оно. 
Понятие бесшовной транспортной системы и её детерминанты в отечественной научной литературе впервые упоминаются в работе Б. М. Лапидуса и Л. В. Лапидус [5]. Авторы подчёркивают, что основой бесшовных транспортных систем для обслуживания устойчивых интенсивных пассажиропотоков может стать только высокопроизводительный транспорт: традиционный железнодорожный, высокоскоростной, в том числе на основе технологии магнитной левитации.

Л. П. Левицкая [7] даёт классификацию городских транспортных систем по критерию согласованности функционирования видов пассажирского транспорта и описывает основные преимущества развития бесшовных транспортных систем в мегаполисах.

В работе С. П. Вакуленко [1] описаны характеристики бесшовных транспортных систем (автор использует термин «интермодальные перевозки») и принципы комбинирования видов общественного пассажирского транспорта.

Н. А. Журавлева и И. Л. Сакович [3] приводят экономическое описание эффектов, возникающих в результате интеграции железнодорожных пригородных перевозок в городские транспортные системы и их взаимодействия с другими видами пассажирского транспорта.

Также развиваются проекты мультимодальных перевозок в городском и пригородном сообщении. Здесь можно привести в пример не только проект Московского центрального кольца, но и пригородных пассажирских компаний, обслуживающих другие мегаполисы. Например, АО «Краспригород» и ряд других ППК реализуют на своих полигонах обслуживания проект «Городская электричка», который способствует росту доходов и интенсивности использования ресурсов пригородного комплекса.

Хотя приведённые примеры связаны с мультимодальными перевозками, их нельзя отождествлять с формированием бесшовных транспортных систем в полном смысле этого слова. Во-первых, потому, что на сегодняшний день существуют в основном локальные проекты, реализуемые на отдельных маршрутах или вблизи мегаполисов. Во-вторых, потому, что бесшовная транспортная система должна иметь все необходимые элементы транспортной инфраструктуры, обеспечивающие возможность интеграции её участников и синхронизации движения транспорта. Кроме того, требуется постоянная координация действий её участников, в том числе в оперативном режиме (в рамках координационных центров, совместных проектов в специальных командах, выделенных структурных подразделений или бизнесединиц). Соответственно, её формирование и развитие требует определённых инвестиций. Однако не все участники рынка транспортных услуг осознают выгоды согласованного взаимодействия и проявляют интерес к инвестированию в подобные проекты. В связи с этим приобретает актуальность разработка адекватных методов экономической оценки развития мультимодальных перевозок, позволяющих оценить их результаты и затраты для каждого стейкхолдера. 
Из обзора эволюции подходов к управлению транспортными системами можно сделать очевидный вывод о том, что интермодальная (бесшовная) транспортная система должна целенаправленно формироваться в крупных городах и мегаполисах. Сочетая преимущества различных видов городского транспорта, она способна сократить общественные издержки и удовлетворить растущий спрос на перевозки. Основой бесшовной транспортной системы мегаполиса может стать рельсовый транспорт, поскольку именно он обеспечивает удовлетворение массового спроса на перевозки в пиковые часы. Приоритизация рельсового транспорта достигается путём увеличения размеров движения, регулирования транспортных тарифов и ограничительных мер в отношении других видов транспорта, прежде всего личного.

Использование иных видов городского общественного транспорта также целесообразно для решения определённых задач. Во-первых, они могут использоваться с целью подвоза пассажиров к станциям рельсового транспорта. Во-вторых, применение иных видов транспорта может осуществляться с целью развития конкуренции на дублирующих маршрутах и для перевозок пассажиров между специализированными зонами конурбаций во внепиковые часы.

Что касается личного автотранспорта, в бесшовных транспортных системах мегаполисов необходим контроль его использования, в том числе в форме взимания определённой платы за въезд на территорию города, в определённые районы или в исторический центр. Кроме того, ограничение использования личного автотранспорта в мегаполисах может осуществляться за счёт организации платных парковок. Ограничительные меры объясняются нерациональностью использования дефицитного городского пространства одним автомобилем, который обладает минимальной производительностью. Кроме того, принимается во внимание экологическая нагрузка: в пересчёте на одного пассажира выбросы вредных веществ личным автотранспортом гораздо больше по сравнению с выбросами общественного транспорта.

\section{2. Влияние цифровизации на городские транспортные системы}

Начиная с 1990-х годов стремительными темпами развиваются информационные технологии. Их интенсивное использование в различных отраслях промышленности и сфере услуг называется цифровизацией. Это процесс, приводящий к кардинальному изменению технологий производства продукции и оказания услуг и переходу к четвёртому технологическому укладу. К примерам, иллюстрирующим результаты цифровизации, можно отнести предоставление услуг 3D-печати, использование блокчейн-технологий в контрактной работе, онлайн-торговлю, онлайн-банкинг и др. Особую значимость приобретает ускоренное внедрение цифровых технологий в транспортную отрасль, что подчёркивается в работах Б. М. Лапидуса [6], Е. Н. Розенберга и В. В. Батраева [8], А. Кирилловой [4]. Цифровые технологии применяются в том числе в планировании и организации пассажирских пере- 
возок в мегаполисах. Эксперты оценивают эффекты от их использования как весьма значительные.

На рис. 2 приведены ключевые цифровые технологии, которые находят применение в городских транспортных системах.

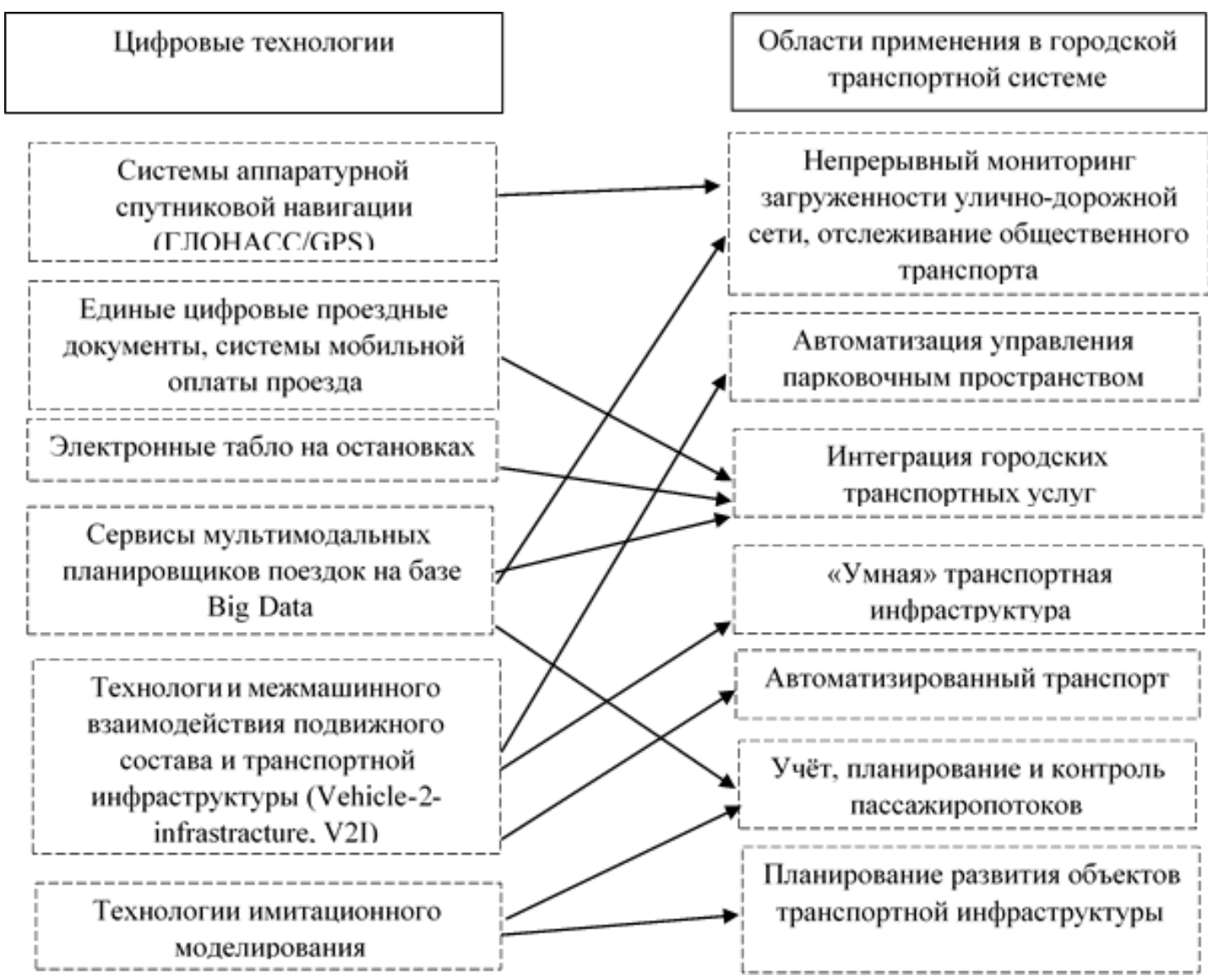

Рис. 2. Использование цифровых технологий

в городских транспортных системах

Уровень развития современных информационных технологий (появление Internet of things и Big Data) создаёт условия для появления интеллектуальных транспортных систем, позволяющих управлять транспортом в режиме реального времени. Как было уже показано выше, важной задачей сити-логистики является развитие согласованного взаимодействия видов транспорта и формирования бесшовных транспортных систем. Одна из прикладных задач формирования бесшовной транспортной системы - организация оказания комплексных транспортных услуг в форме смешанных перевозок. Термин «смешанная перевозка» определяется в проекте Федерального закона «О прямых смешанных (комбинированных) перевозках» как 
перевозка грузов, пассажиров, багажа различными видами транспорта по единому транспортному документу, оформленному на весь путь следования.

С. П. Вакуленко определяет интермодальные пассажирские перевозки как перевозки, которые осуществляются операторами двух и более видов транспорта с применением единых перевозочных документов (билета и квитанции сверхнормативного багажа) на весь маршрут перевозки. В случае, если смешанная перевозка осуществляется операторами трёх и более видов транспорта, допускается использование термина мультимодальная перевозка [1].

Таким образом, неотъемлемым признаком комплексной транспортной услуги для пассажиров является наличие единого проездного документа на весь путь следования.

Комплексные транспортные услуги возможно развивать только по инициативе самих участников рынка - транспортных организаций, осуществляющих городские и пригородные пассажирские перевозки. Важным резервом сокращения времени на обслуживание пассажиров является развитие приложений для мобильных устройств, позволяющих планировать поездку, а также применение единых билетов на несколько видов транспорта.

Как видно из рис. 2, спектр применения цифровых технологий довольно широк, однако в рамках одного исследования рассмотреть все перечисленные возможности невозможно. Поэтому далее будет более подробно рассмотрено применение технологий имитационного моделирования для оценки эффектов внедрения алгоритма «умного» дорожного регулирования.

\section{3. Использование «умных» технологий дорожного регулирования в мегаполисах}

Одно из перспективных направлений цифровизации городских транспортных систем - внедрение алгоритмов дорожного регулирования, основанных на принципах нечёткой логики, теории очередей или на базе генетического алгоритма. Работу подобных алгоритмов представляется целесообразным предварительно оценивать, используя имитационное моделирование. Из-за возрастающей производительности вычислительных машин возможность моделирования и применения виртуальной реальности в процессе городского планирования становится более практичной и осуществимой.

Анализ публикаций показал, что в настоящий период за рубежом проводится больше прикладных исследований, связанных с моделированием работы объектов транспортной инфраструктуры, чем в России.

В зарубежных публикациях по теме преобладают результаты исследований, нацеленных на выявление существенных факторов, влияющих на параметры работы моделируемых объектов (светофоров), и последующую оптимизацию режима их 
работы. В работе Mădălin-Dorin Pop [10] обоснованы перспективы использования технологии агентного моделирования в программной среде AnyLogic для решения подобных задач. Автор подчёркивает необходимость учёта пассажирских потоков при управлении дорожным движением, а также важность калибровки имитационных моделей для отражения реальной ситуации на улично-дорожной сети.

Большинство имеющихся исследований, посвященных моделированию работы объектов транспортной инфраструктуры, нацелены на анализ построенной имитационной модели и оптимизацию параметров её работы.

Совместно с магистрантом НИУ «Высшая школа экономики» Д. М. Соловьёвым мы разработали имитационную модель, иллюстрирующую работу одного из перекрёстков в Санкт-Петербурге. Результаты нашего совместного исследования опубликованы в научном журнале «Логистика и управление цепями поставок», № 4 (2020 г.) [2].

В качестве объекта моделирования был выбран перекрёсток в Центральном районе города - пересечение Свечного пер. и ул. Марата. Выбранный объект отличается дефицитом пропускной способности во время часов пиковой нагрузки. Предлагается оборудовать данный объект светофорами и сенсорами учёта машин, оснащёнными «умной» системой дорожного регулирования. Предполагаемая конфигурация объекта приведена на рис. 3 .

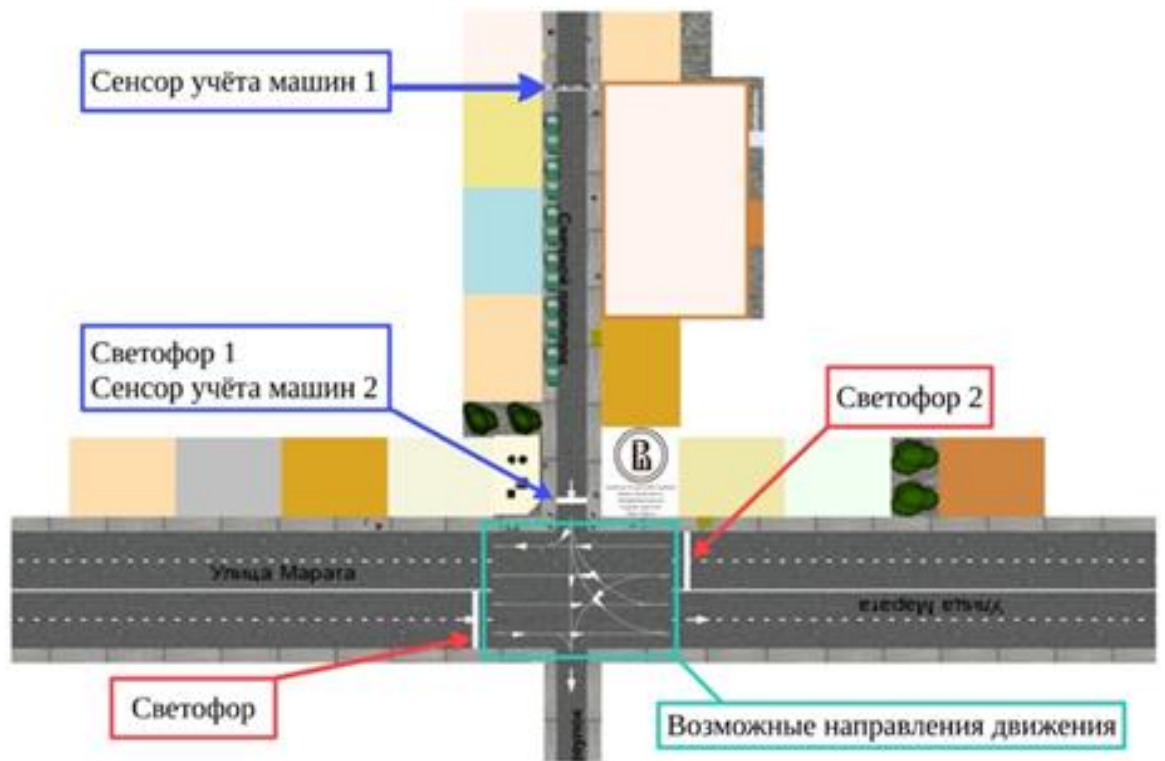

Рuc. 3. Предполагаемая конфигурация объекта дорожной инфраструктуры

Как видно из рис. 3, на перекрёстке предлагается установить три светофора, регулирующих автомобильное движение. Светофор 1, расположенный на Свечном 
переулке, контролируется алгоритмом, который опирается на показания сенсора учёта машин. Последний находится выше по направлению переулка. Для оптимизации процесса регулирования и решения проблемы транспортных заторов на Свечном переулке Д. М. Соловьёвым был разработан алгоритм, опирающийся на теорию очередей [2]. Эксперимент, иллюстрирующий работу выбранного объекта при описанных выше условиях, проводился в программной среде AnyLogic с использованием технологии агентного моделирования.

Алгоритм работы модели схематично изображён на рис. 4. Поясним значение элементов, изображенных на рис. 4. "SideStreetCheck” является циклом, обновляющим данные сенсора каждые 100 миллисекунд. Пока сенсор учёта машин 1 не обнаружит машину, цикл будет сохранять следующую конфигурацию светофоров (рис. 3): Светофор - зелёный, Светофор 1 - красный, Светофор 2 - красный. При обнаружении сенсором учёта машин 1 автомобиля следует блок “allYellow”, задающий всем светофорам системы жёлтый сигнал продолжительностью 3 секунды.

Спустя 3 секунды жёлтого сигнала система переводит светофоры улицы Марата на запрещающий движение сигнал, при этом открывая движение со стороны Свечного переулка на 15 секунд (Светофор 1 на рис. 3).

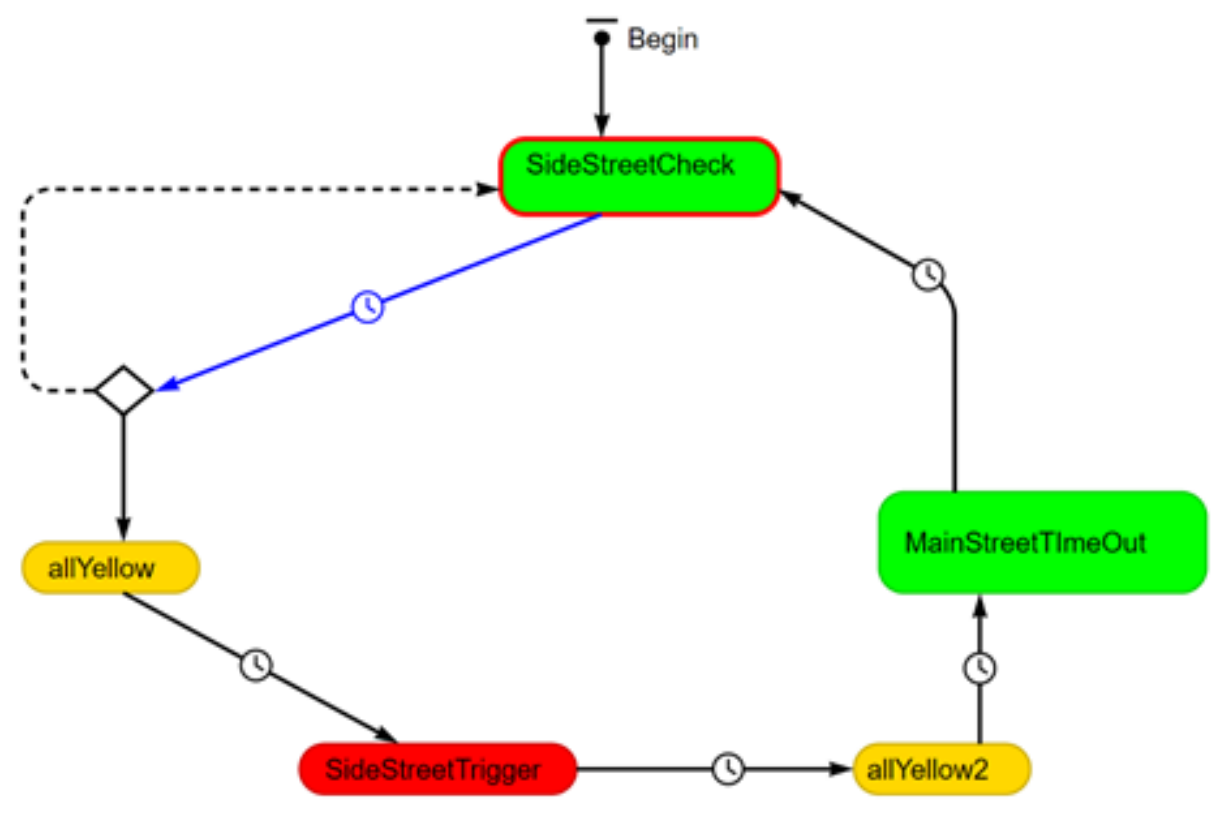

Puc. 4. Схематичное изображение алгоритма дорожного регулирования

Затем снова следует 3-секундный жёлтый сигнал светофора, задаваемый блоком “allYellow2”. Во избежание злоупотребления разработанным алгоритмом в 
случаях, когда поток машин со стороны Свечного переулка равномерен, был добавлен блокирующий элемент "MainStreetTimeOut". Он призван ограничить количество блокировок улицы Марата, снижая транспортную напряжённость на дороге.

Таким образом, количество срабатываний цикла по Свечному переулку не может превышать одного раза в 60 секунд. Минимальная продолжительность зелёного сигнала светофора для улицы Марата будет равна 60 секундам соответственно.

Анализ результатов имитационного моделирования позволил сделать вывод о том, что предложенный алгоритм эффективно справляется с задачей дорожного регулирования на выбранном перекрёстке (рис. 5). Количество автомобилей в очереди перед светофором за время эксперимента в среднем составляло 2 ед.

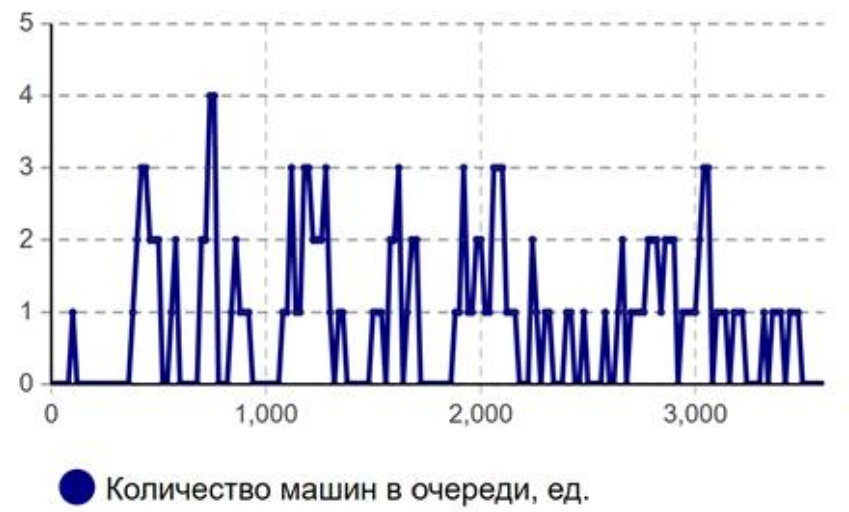

Puc. 5. Динамика числа автомобилей в очереди перед светофором, ед.

Как видно из рис. 5, максимальное число автомобилей в очереди перед светофором в ходе эксперимента составляло 4 ед., что свидетельствует о результативности использования предложенного алгоритма.

Нами также было проанализировано среднее время в пути, которое тратят автомобили, осуществляющие дорожные манёвры со Свечного переулка. Для демонстрации результатов эксперимента проведён сравнительный анализ затраченного времени в ситуации «с алгоритмом» и «без алгоритма» по направлениям движения, результаты которого представлены на рис. 6 .

Из рис. 6 видно, что применение предложенного алгоритма дорожного регулирования обеспечивает значительное сокращение затрат времени ожидания автомобилей и их общего времени в пути на выбранном участке. Таким образом, предложенный алгоритм результативен, поскольку обеспечивает рост пропускной способности объекта транспортной инфраструктуры и экономию времени за счёт сокращения ожидания разрешающего сигнала светофора. 


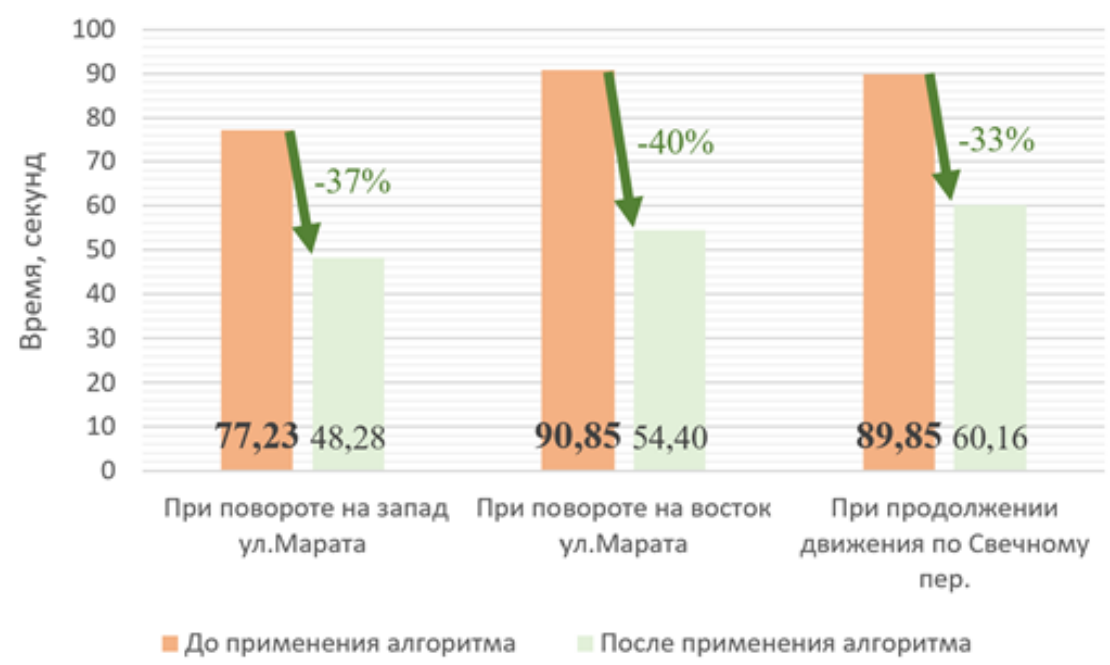

Puc. 6. Результаты сравнения показателей затраченного времени до и после применения предложенного алгоритма

Экономическая оценка эффектов цифровизации и формирования бесшовных городских транспортных систем - достаточно сложная задача, требующая комплексного подхода к решению, в процессе которого возникает ряд трудностей. Однако очевидно, что проекты цифровизации на транспорте генерируют значительные эффекты для всех групп стейкхолдеров и способствуют лучшей координации всех видов транспорта. Поэтому можно заключить, что подобные проекты требуют как можно более полной идентификации положительных эффектов и их оценки для определения рациональной структуры источников финансирования и обоснования степени участия в них представителей бизнес-сообщества, общественных организаций и государственных структур.

\section{Список литературы}

1. Вакуленко, С. П. Интермодальные перевозки в пассажирском сообщении с участием железнодорожного транспорта / С. П. Вакуленко. - Москва : Учеб.-метод. центр по образованию на железнодорожном транспорте, 2013. -263 с.

2. Волкова, Е. М. Применение инструментов имитационного моделирования в сити-логистике и экономическая оценка полученных результатов / Е. М. Волкова, Д. М. Соловьев // Логистика и управление цепями поставок. - 2020. - № 4 (99). С. $50-56$.

3. Журавлева, Н. А. Интеграция железнодорожных перевозок в транспортные системы городских агломераций / Н. А. Журавлева, И. Л. Сакович // Транспорт Российской Федерации. - 2018. - № 6 (79). - С. 26-29. 
4. Кириллова, А. Цифровые транспортные системы - близкая реальность // Интеллектуальные транспортные системы России. - 2018. - № 6. - C. 50-57. - URL: http://itsrussiaforum.ru/magazine/magazine_6.pdf (дата обращения: 15.03.2021).

5. Лапидус, Б. М. Гладкая бесшовная транспортная система - инновационная модель будущего: природа, сущность, детерминанты качества / Б. М. Лапидус, Л. В. Лапидус // Вестник Московского университета. Сер. 6, Экономика. - 2017. № 2. - C. 45-64.

6. Лапидус, Б. М. О влиянии цифровизации и Индустрии 4.0 на перспективы развития железнодорожного транспорта // Бюллетень Объединенного Ученого совета ОАО «РЖД». - 2018. - № 1. - С. 1-8.

7. Левицкая, Л. П. Стратегия развития городской транспортной системы Л. П. Левицкая, М. А. Кретов // Экономика железных дорог. - 2016. - № 9. - С. 68-74.

8. Розенберг, Е. Н. О стратегии развития Цифровой железной дороги / Е. Н. Розенберг, В. В. Батраев// Бюллетень Объединенного Ученого совета ОАО «РЖД». - 2018. - № 1. - С. 9-27.

9. Шабарова, Э. В. Система пассажирского транспорта города и агломерации: системный анализ и проектирование / Э. В. Шабарова. - Рига : Знание, 1981. - 280 с.

10. Pop, Mădălin-Dorin. Traffic lights management using optimization tool // Procedia - Social and Behavioral Sciences. - 2018. - No. 238. - P. 323-330.

\section{References}

1. Vakulenko S. P. Intermodal'nye perevozki v passazhirskom soobshchenii s uchastiem zheleznodorozhnogo transporta [Intermodal transport in passenger traffic involving rail transport]. Moscow: Uchebno-metodicheskij centr po obrazovaniyu na zheleznodorozhnom transporte, 2013. $263 \mathrm{p}$.

2. Volkova E., Solovev D. Primenenie instrumentov imitatsionnogo modelirovaniya v siti-logistike i ekonomicheskaya otsenka poluchennykh rezul'tatov [Implementation of simulation modeling in city logistics and economic evaluation of the results]. Logistika $i$ upravlenie tsepyami postavok, 2020, vol. 99, no. 4, pp. 50-56.

3. Zhuravleva N. A., Sakovich I. L. Integratsiya zheleznodorozhnykh perevozok v transportnye sistemy gorodskikh aglomeratsii [Integration of railways in urban transport systems]. Transport Rossiiskoi Federatsii, 2018, vol. 79, no. 6, pp. 26-29.

4. Kirillova A. Tsifrovye transportnye sistemy - blizkaya real'nost' [Digital transport systems - close reality]. Intellektual'nye transportnye sistemy Rossii, 2018, no. 6, pp. 50-57. Available at: http://itsrussiaforum.ru/magazine/magazine_6.pdf (accessed 09 February 2021).

5. Lapidus B. M., Lapidus L. V. Gladkaya besshovnaya transportnaya sistema - innovatsionnaya model' budushchego: priroda, sushchnost', determinanty kachestva [Seamless transport system - innovative model of future: essence, nature, quality determinants]. Vestnik Moskovskogo universiteta. Seriya 6, Ekonomika, 2017, no. 2, pp. 45-64. 
6. Lapidus B. M. O vliyanii tsifrovizatsii i Industrii 4.0 na perspektivy razvitiya zheleznodorozhnogo transporta [On the impact of digitalization and Industry 4.0 on the prospects for the development of railway transport]. Byulleten' Ob"edinennogo Uchenogo soveta $O A O \ll R Z h D », 2018$, no. 1, pp. 1-8.

7. Levickaya L. P., Kretov M. A. Strategiya razvitiya gorodskoi transportnoi sistemy [Strategy for the development of the urban transport system]. Ekonomika zheleznykh dorog, 2016, no. 9, pp. 68-74.

8. Rozenberg E. N., Batraev V. V. O strategii razvitiya Tsifrovoi zheleznoi dorogi [About the Digital Railway Development Strategy]. Byulleten' Ob"edinennogo Uchenogo soveta $O A O \ll R Z h D », 2018$, no. 1, pp. 9-27.

9. Shabarova E. V. Sistema passazhirskogo transporta goroda i aglomeratsii: sistemnyi analiz i proektirovanie [City and agglomeration Passenger Transport System: System analysis and design], Riga: Znanie, 1981. 280 p.

10. Pop Mădălin-Dorin. Traffic lights management using optimization tool. Procedia - Social and Behavioral Sciences, 2018, no. 238, pp. 323-330. 